\title{
Validation of a satellite-based cyclogenesis technique over the North Indian Ocean
}

\author{
Suman Goyal ${ }^{1, *}$, M Mohapatra ${ }^{1}$, Ashish Kumar ${ }^{1}$, S K Dube ${ }^{2}$, \\ Kushagra RAJENDRA ${ }^{3}$ and P GOSWAMI ${ }^{1}$ \\ ${ }^{1}$ India Meteorological Department, Mausam Bhawan, Lodi Road, New Delhi 110 003, India. \\ ${ }^{2}$ Amity University, Jaipur, Rajasthan 303 007, India. \\ ${ }^{3}$ Amity University, Gurgaon, Haryana 122 413, India. \\ *Corresponding author.e-mail: suman.imd@gmail.com
}

Indian region is severely affected by the tropical cyclones (TCs) due to the long coast line of about $7500 \mathrm{~km}$. Hence, whenever any low level circulation (LLC) forms over the Indian Seas, the prediction of its intensification into a TC is very essential for the management of TC disaster. Satellite Application Centre (SAC) of Indian Space Research Organization (ISRO), Ahmedabad, has developed a technique to predict TCs based on scatterometer-derived winds from the polar orbiting satellite, QuikSCAT and Oceansat-II. The India Meteorological Department (IMD) has acquired the technique and verified it for the years 2010-2013 for operational use. The model is based on the concept of analogs of the sea surface wind distribution at the stage of LLC or vortex (T1.0) as per Dvorak's classifications, which eventually leads to cyclogenesis (T2.5). The results indicate that the developed model could predict cyclogenesis with a probability of detection of $61 \%$ and critical success index of 0.29 . However, it shows high overprediction of the model is better over the Bay of Bengal than over Arabian Sea and during post-monsoon season (September-December) than in pre-monsoon season (March-June).

\section{Introduction}

One of the severe weather systems which affect the Indian region is the tropical cyclone (TC). They originate in the Bay of Bengal (BOB) or Arabian Sea (ARS) mainly in pre-monsoon (March-June) and post-monsoon (September to December) seasons from low level circulation (LLC), intensify gradually and move west-northwestwards (IMD 2013). When they cross the coast, torrential rain, high wind speed and storm surge cause havoc in terms of loss of life and properties. Entire east and west coast districts of India are prone to TC activity, though the proneness varies from district to district depending upon the frequency and intensity of the TC crossing the district and the associated heavy rains, winds and storm surges over the district (Mohapatra et al. 2012a; Mohapatra 2015). Hence, the early detection and prediction of cyclogenesis over the north Indian Ocean (NIO) can provide more lead time and also accurate early warning of TCs. The NIO being the data sparse region with limited ground observations and buoys/ships (Mohapatra et al. 2012b), satellite plays a dominant role for early detection and prediction of cyclogenesis. The satellite data, which are used to monitor TC genesis, are infrared (IR) and visible imageries from Kalpana-1 and INSAT-3D, scatterometric winds from microwave satellites Oceansat-II and ASCAT and microwave imageries from Naval Research

Keywords. Tropical cyclones; cyclogenesis; Dvorak's technique; scatterometeric winds. 
Table 1. Total number of cyclonic vortices (T1.0) formed during 2010-2013 over the north Indian Ocean.

\begin{tabular}{lcc}
\hline $\begin{array}{l}\text { Category of low } \\
\text { pressure systems (LPS) }\end{array}$ & $\begin{array}{c}\text { Maximum T No. } \\
\text { associated with LPS }\end{array}$ & $\begin{array}{c}\text { Frequency } \\
\text { of LPS }\end{array}$ \\
\hline Low pressure area (L) & $\mathrm{T} 1.0$ & 13 \\
Depression (D) & $\mathrm{T} 1.5$ & 08 \\
Deep depression (DD) & $\mathrm{T} 2.0$ & 08 \\
Cyclonic storm (CS) & $\mathrm{T} 2.5-\mathrm{T} 3.0$ & 05 \\
Severe cyclonic storm (SCS) & $\mathrm{T} 3.5$ & 03 \\
Very severe cyclonic storm (VSCS) & T4.0-T6.0 & 04 \\
Extremly severe cyclonic storm (ESCS) & & 02 \\
Super cyclonic storm (SuCS) & $\mathrm{T} 6.5$ or more & 00 \\
Total & & 43 \\
\hline
\end{tabular}

Laboratory (NRL) Satellite Meteorology website (http://www.nrlmry.navy.mil/tc_pages/tc_home. html). Whenever any LLC forms over the sea, meteorologists of the nearby countries show keen interest to know the possible cyclogenesis. The cyclogenesis is characterised by a decrease in the sea level pressure and an intensification of LLC leading to increase in maximum sustained surface wind speed (MSW), quantitatively. When the MSW, at a surface level associated with the low pressure system, becomes 17 knots or more (IMD 2013), it is called a depression over the NIO. It becomes a cyclonic storm if the MSW is 34 knots or more. The intensity of the low pressure system is also defined based on Dvorak's technique (Dvorak 1984) using satellite imageries. In this technique, the intensity is defined with an assigned number in a scale of 1-8 in an interval of 0.5 ; this number is called as $\mathrm{T}$ number. Different stages of tropical disturbances are low pressure area (T1.0) with MSW of less than 17 knots, depression (T1.5) with MSW of 17-27 knots, deep depression (T2.0) with MSW of 28-33 knots, cyclonic storms (T2.5-T3.0) with MSW of 34-47 knots, severe cyclonic storms (T3.5) with MSW of 48-63 knots, very severe cyclonic storms (T4.0-T4.5) with MSW of 64-89, extremely severe cyclonic storms (T5.0-T6.0) with MSW 90-119 knots and super cyclonic storms (T6.5-T8.0) with MSW of 120 knot and above (table 1) (Dvorak 1984; IMD 2013).

The necessary conditions for tropical cyclogenesis include thermodynamic conditions, viz., high sea surface temperature, high mid-tropospheric humidity, and conditionally unstable layer from surface to mid-troposphere and dynamic conditions, viz., weak tropospheric vertical wind shear, significant low-level relative vorticity, and sufficient coriolis parameter (Gray 1975). Tropical cyclogenesis has been studied by many investigators during the last several decades (Charney and Eliassen 1964; Ooyama 1969; Zehr 1992; Demirci et al. 2007; Pineros et al. 2010; Kotal et al. 2014) based on above parameters. A technique has been developed at the National Oceanic and Atmospheric Administration (NOAA) by Schumacher et al. (2009) for estimating the 24-h probability of TC formation within each $5^{\circ} \times 5^{\circ}$ latitude-longitude sub-region in the Atlantic, eastern Pacific, and western Pacific tropical basins. This product uses both environmental parameters from Automated TC Forecasting (ATCF) best tracks and National Centers for Environmental Prediction (NCEP) Global Forecast System (GFS) data fields as well as convective parameters from the GOES-E, GOES-W, and MTSAT-1R water vapour imagery. This algorithm was developed using a two-step process that involves (1) screening out data points where TC formation is highly unlikely and (2) linear discriminant analysis. The resultant discriminant function values are interpolated to 24 -h TC formation probabilities. Verification of the TCFP (TC Formation Probability) product, using both the Brier skill score and relative operating characteristic, showed that the product possesses skill with respect to both the null hypothesis and climatology. A genesis potential parameter (GPP) was developed by Kotal et al. (2009) which consists of two thermodynamic and two dynamical variables. The dynamical variables used in the computation are low-level relative vorticity and vertical wind shear. The thermodynamic variables are middle tropospheric relative humidity and instability. The variables are derived from the NCEP reanalysis data. The result shows that composite GPP values are 11.1, 12.3, 13.3 , and 13.5 for developing systems (T3.0 or more) and 3.4, 4.2, 4.6, and 2.7 for non-developing systems $(\mathrm{T}<3.0)$ at $\mathrm{T}$. Nos. 1.0, 1.5, 2.0, and 2.5, respectively. When applied at the stage of T. Nos. $1.0,1.5$, and 2.0, the GPP values are found to be around three times greater for developing systems than for non-developing systems. However, these dynamical statistical models performance is highly dependent on model characteristics and initial conditions. 
Due to unavailability of conventional observations over the sea surface, satellite data are mostly employed and found to be a useful tool to study and understand cyclogenesis (Zehr 1988; Liu et al. 1995; Katsaros et al. 2001; Sharp et al. 2002; Li et al. 2003; Chelton et al. 2004; Wang et al. 2007, 2008). The microwave scatterometers onboard polar-orbiting satellites have helped to study the early stages of cyclogenesis (Liu et al. 1995) as they provide sea surface winds. The sea-winds scatterometer, onboard the QuikSCAT satellite that infers surface wind speed and direction, has encouraged various studies regarding early identification of tropical disturbances (Katsaros et al. 2001; Sharp et al. 2002). An objective technique to detect tropical disturbances associated with the early stages of tropical cyclogenesis by the identification of surface vorticity and wind speed signatures from QuikSCAT and GOES imagery has been discussed by Hite et al. (2007). A relationship between the mean relative vorticity of surface winds derived from the QuikSCAT satellite and the cyclogenesis has also been discussed by Wang et al. (2007) and Bourassa and McBeth-Ford (2010). However, the prediction of cyclogenesis based on vorticity threshold may suffer due to the fact that (i) due to partial coverage of scatterometer instrument, the true vorticity maxima might not appear in the observed scenes, and (ii) due to the well-known problem, i.e., directional ambiguity in scatterometer wind observations, the computation of vorticity may be erroneous at certain points. Wind direction ambiguity problem is more serious in cyclonic environments owing to contamination of backscattering signals due to high precipitation. To overcome these limitations, a new technique, based on the matching of large-scale wind vector fields, has been developed by Satellite Application Centre (SAC), Ahmedabad (Jaiswal and Kishtawal 2011) based on scatterometer-derived winds from the QuikSCAT and Oceansat-II satellites for the period 2000-2008. Details about the scatterometric products from QuikSCAT and Oceansat-II have been discussed by Jaiswal and Kishtawal (2011). The technique is based on the ocean wind vectors derived from the sea-wind scatterometer on the QuikSCAT satellite. The technique is based on similarity of a given wind pattern with wind vector signatures of developing systems, available from the past observations. A database has been formed using the QuikSCAT observed vector wind patterns associated with the early stages of $\mathrm{TC}$ that developed in the NIO during the years 20002008. The prediction of the possibility of cyclogenesis, in a given scene is determined by matching it with all the archived scenes in the database using a vector block matching algorithm. The system is predicted as developing, if its matching index (MI) exceeds the predetermined threshold value $(0.6)$.

Jaiswal and Kishtawal (2011) have validated the technique based on continuous data for the period 2007-2009 for active cyclone months excluding the scenes archived in the database and found all the tropical disturbances that developed into TC during the period were predicted correctly with two false alarms. The probability of detection (POD) was calculated to be 0.93 . However the validation study is based on limited cases as there were only four VSCS (very severe cyclonic storm), one SCS (severe cyclonic storm), and nine CS (cyclonic storm). Further the analysis and validation is based on the cyclogenesis data of the Joint Typhoon Warning Centre (JTWC), USA. They have not verified the technique with IMD's best track parameters. It may be mentioned that due to different tools, techniques and procedures, different agencies like the JTWC and IMD differ from each other on time of detection as well as frequency of detections of cyclogenesis in terms of $\mathrm{T}$ number based on Dvorak's technique (Mohapatra et al. 2012b). Hence a study has been undertaken to verify the performance of the technique developed by Jaiswal and Kishtawal (2011) for operational use, based on the cyclogenesis data of IMD during 2010-2013. The study will be helpful for operationalisation of the technique and a better understanding of the cyclogenesis process over the region.

\section{Data and methodology}

During the validation period (2010-2013), a total of 43 tropical systems (T1.0 and above) formed in $\mathrm{BOB}$ and $\mathrm{ARS}$ as shown in table 2 and figure 1. To run the cyclogenesis prediction model, scatterometric wind data of Oceansat-II in hdf5 (hierarchical data format) format are required. These are available in the website of National Remote Sensing Centre (NRSC) (http://www.nrsc.gov.in/). India's polar-orbiting satellite, Oceansat-II, was launched by ISRO on 23rd September 2009, with three payloads, namely, the Ocean Color Monitor, $\mathrm{Ku}$-band Scatterometer, and Radio Occultation Sounder for atmospheric studies. The Oceansat-II satellite was launched into a near polar sun-synchronous orbit of $720 \mathrm{~km}$ altitude with the local time of equatorial crossing in the descending node at 12 noon \pm $10 \mathrm{~min}$. The orbital inclination with equatorial plane is $98.28^{\circ}$. The orbital and recurrent periods of the satellite are $99.31 \mathrm{~min}$ and two days, respectively. The distances between adjacent traces and successive ground tracks of the orbit are 1382 and $2764 \mathrm{~km}$, respectively. The Ku-band pencil beam scatterometer in OceanSat-II is an active microwave radar operating at $13.515 \mathrm{GHz}$. Surface 
Table 2. Details of Synoptic systems with T No. $\geq 1.0$ considered in the study.

Duration of system

\begin{tabular}{|c|c|c|c|c|c|c|}
\hline \multirow[b]{2}{*}{ Sl. no. } & \multirow{2}{*}{$\begin{array}{l}\text { Date and time } \\
\text { of formation }\end{array}$} & \multirow{2}{*}{$\begin{array}{c}\text { Date and time } \\
\text { of landfall }\end{array}$} & \multicolumn{3}{|c|}{ Maximum intensity reached } & \multirow[b]{2}{*}{ Basin } \\
\hline & & & T no. & Date and time & Name & \\
\hline 1 & $16.05 .10(1200)$ & $20.05 .10(0600)$ & 3.5 & $19.05 .10(0200)$ & CS (Laila) & $\mathrm{BOB}$ \\
\hline 2 & $16.05 .10(1200)$ & $22.05 .10(2100)$ & 2.5 & $21.05 .10(1000)$ & CS Bandhu & ARS \\
\hline 3 & $30.05 .10(1200)$ & $06.06 .10(1200)$ & 4.5 & $02.06 .10(0800)$ & CS (Phet) & ARS \\
\hline 4 & $06.10 .10(0300)$ & $08.10 .10(0600)$ & 1.5 & $07.10 .10(0300)$ & $\mathrm{D}$ & $\mathrm{BOB}$ \\
\hline 5 & $12.10 .10(0300)$ & $15.10 .10(1800)$ & 2.0 & $15.10 .10(0300)$ & DD & $\mathrm{BOB}$ \\
\hline 6 & $20.10 .10(0600)$ & $22.10 .10(1400)$ & 5.5 & $22.10 .10(1000)$ & ESCS (Giri) & $\mathrm{BOB}$ \\
\hline 7 & $02.11 .10(1500)$ & $07.11 .10(1800)$ & 3.5 & $05.11 .10(2100)$ & CS (Jal) & $\mathrm{BOB}$ \\
\hline 8 & $14.11 .10(0900)$ & $16.11 .10(0300)$ & 1.0 & $14.11 .10(0900)$ & WML & $\mathrm{BOB}$ \\
\hline 9 & $02.12 .10(1200)$ & $03.12 .10(0900)$ & 1.0 & $02.12 .10(1200)$ & WML & ARS \\
\hline 10 & $02.02 .11(0300)$ & $09.02 .11(1200)$ & 1.5 & $02.02 .11(0600)$ & $\mathrm{D}$ & $\mathrm{BOB}$ \\
\hline 11 & $28.03 .11(1200)$ & $30.03 .11(1500)$ & 1.0 & $28.03 .11(1200)$ & WML & $\mathrm{BOB}$ \\
\hline 12 & $06.06 .11(0300)$ & $12.06 .11(0900)$ & 1.5 & $11.06 .11(0900)$ & $\mathrm{D}$ & ARS \\
\hline 13 & $15.06 .11(1200)$ & $16.06 .11(0900)$ & 1.5 & $16.06 .11(0300)$ & $\mathrm{D}$ & $\mathrm{BOB}$ \\
\hline 14 & $13.09 .11(0300)$ & $14.09 .11(0600)$ & 1.0 & $13.09 .11(0300)$ & WML & $\mathrm{BOB}$ \\
\hline 15 & $21.09 .11(0600)$ & $22.09 .11(1200)$ & 1.5 & $22.09 .11(0300)$ & $\mathrm{D}$ & $\mathrm{BOB}$ \\
\hline 16 & $17.10 .11(0300)$ & $19.10 .11(1300)$ & 2.0 & $19.10 .11(0300)$ & DD & $\mathrm{BOB}$ \\
\hline 17 & $28.10 .11(0600)$ & $04.11 .11(0900)$ & 2.5 & $02.11 .11(0300)$ & CS (Keila) & ARS \\
\hline 18 & $05.11 .11(0600)$ & $10.11 .11(1800)$ & 2.0 & $08.11 .11(0000)$ & $\mathrm{DD}$ & ARS \\
\hline 19 & $25.11 .11(1500)$ & $01.12 .11(1500)$ & 2.0 & $27.11 .11(2100)$ & DD & ARS \\
\hline 20 & $25.12 .11(0330)$ & $30.12 .11(0100)$ & 4.5 & $29.12 .11(0300)$ & CS (Thane) & $\mathrm{BOB}$ \\
\hline 21 & $24.04 .12(1200)$ & $25.04 .12(0900)$ & 1.0 & $24.04 .12(1200)$ & WML & ARS \\
\hline 22 & $27.09 .12(0600)$ & $01.10 .12(1700)$ & 1.0 & $27.09 .12(0600)$ & WML & $\mathrm{BOB}$ \\
\hline 23 & $07.10 .12(2100)$ & $09.10 .12(0900)$ & 1.0 & $07.10 .12(2100)$ & WML & $\mathrm{BOB}$ \\
\hline 24 & $10.10 .12(0300)$ & $11.10 .12(0300)$ & 2.0 & $10.10 .12(1500)$ & DD & $\mathrm{BOB}$ \\
\hline 25 & $22.10 .12(1200)$ & $25.10 .12(1600)$ & 2.5 & $24.10 .12(1200)$ & CS (Murjan) & ARS \\
\hline 26 & $26.10 .12(1500)$ & $31.10 .12(1200)$ & 3.0 & $31.10 .12(0000)$ & CS (Nilam) & $\mathrm{BOB}$ \\
\hline 27 & $16.11 .12(0300)$ & $22.11 .12(0600)$ & 2.0 & 11.11.12(0900) & $\mathrm{DD}$ & $\mathrm{BOB}$ \\
\hline 28 & $27.11 .12(0600)$ & $28.11 .12(1500)$ & 1.0 & $27.11 .12(0600$ & WML & $\mathrm{BOB}$ \\
\hline 29 & $30.11 .12(0300)$ & $03.12 .12(0300)$ & 1.0 & $30.11 .12(0300)$ & WML & $\mathrm{BOB}$ \\
\hline 30 & $22.12 .12(0300)$ & $25.12 .12(0900)$ & 2.0 & $23.12 .12(0000)$ & DD & ARS \\
\hline 31 & $06.01 .13(0600)$ & $08.01 .13(0300)$ & 1.0 & $06.01 .13(0600)$ & WML & $\mathrm{BOB}$ \\
\hline 32 & $08.05 .13(0300)$ & $16.05 .13(0800)$ & 3.0 & $15.05 .13(0400)$ & CS (Mahasen) & $\mathrm{BOB}$ \\
\hline 33 & $26.05 .13(1200)$ & $28.05 .13(0600)$ & 1.0 & $26.05 .13(1200)$ & WML & ARS \\
\hline 34 & $27.05 .13(0600)$ & $29.05 .13(1800)$ & 1.5 & $29.05 .13(0300)$ & $\mathrm{D}$ & $\mathrm{BOB}$ \\
\hline 35 & $04.06 .13(1200)$ & $05.06 .13(1500)$ & 1.0 & $04.06 .13(1200)$ & WML & ARS \\
\hline 36 & $30.07 .13(0600)$ & $30.07 .13(1200)$ & 1.0 & $30.07 .13(0600)$ & WML & $\mathrm{BOB}$ \\
\hline 37 & $07.10 .13(0600)$ & $12.10 .13(1600)$ & 6.0 & $11.10 .13(0300$ & ESCS (Phailin) & $\mathrm{BOB}$ \\
\hline 38 & $21.10 .13(0300)$ & $23.10 .13(0900)$ & 1.5 & $22.10 .13(0600)$ & $\mathrm{D}$ & $\mathrm{BOB}$ \\
\hline 39 & $06.11 .13(0600)$ & $11.11 .13(0000)$ & 2.0 & $08.11 .13(2100)$ & DD & ARS \\
\hline 40 & $08.11 .13(0000)$ & $16.11 .13(1200)$ & 1.5 & $13.11 .13(0000)$ & $\mathrm{D}$ & $\mathrm{BOB}$ \\
\hline 41 & $18.11 .13(0600)$ & $22.11 .13(0800)$ & 3.5 & $21.11 .13(0400)$ & SCS (Helen) & $\mathrm{BOB}$ \\
\hline 42 & $22.11 .13(2100)$ & $28.11 .13(1100)$ & 4.0 & $25.11 .13(2100)$ & VSCS (Lehar) & $\mathrm{BOB}$ \\
\hline 43 & $02.12 .13(0600)$ & $11.12 .13(1800)$ & 4.0 & $08.12 .13(0600)$ & VSCS (Madi) & $\mathrm{BOB}$ \\
\hline
\end{tabular}

wind vectors over global oceans are retrieved from backscattering coefficient data. The incidence angles for inner and outer beams are $48.90^{\circ}$ and $57.60^{\circ}$, respectively. The data of Oceansat-II are available from January 2010 to February 2014. Thereafter, the Oceansat-II became non-operational. The study of cyclogenesis was done from May 2010 to December 2013. There was no TC before May 2010 in year 2010 and during the months January-February, 2014. This is one of the limitations of this study, although we have utilised the maximum available data of Oceansat-II.

Total 1606 numbers of hdf5 data for all the systems have been downloaded with intensity T1.0 onwards. For the sake of convenience, the program was run every day for all the passes, irrespective of the coverage of the system and run with the software to find the Matching Index (MI) to determine the cyclogenesis (figure 2). To define the cyclogenesis, T2.5 corresponding to formation of 


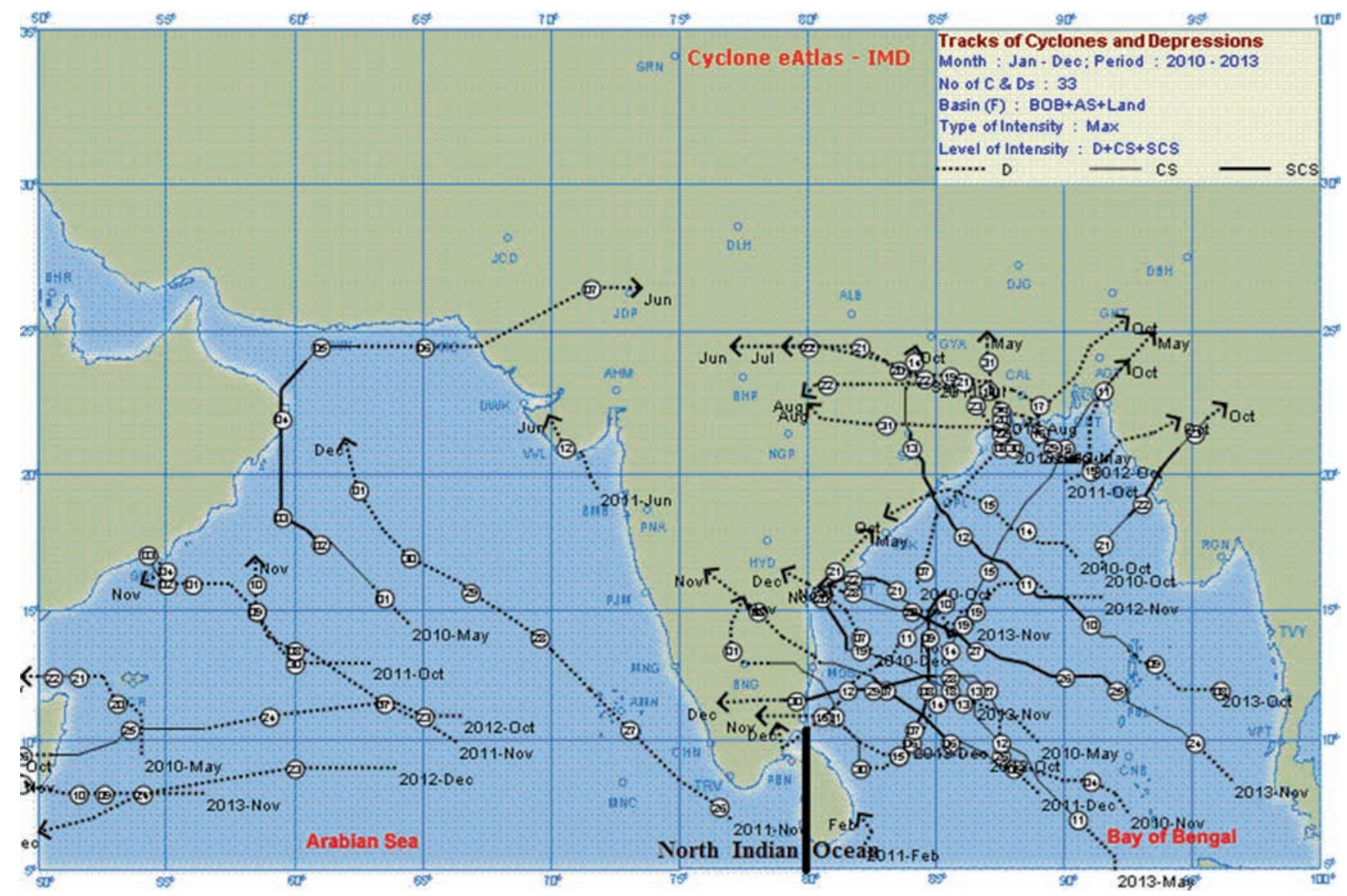

Figure 1. RSMC tracks of cyclone and depression (2010-2013).

cyclonic storm (34 knots or more) as per IMD's classification has been considered in this study. The prediction by the model has been made at the intensity stage of T1.0, T1.5 and T2.0 as declared by IMD. Detailed statistics of low pressure systems are shown in table 3 . The performance of the model has been analysed with respect to basin of formation, season of formation and intensity of cyclogenesis (i.e., T1.0, T1.5, and T2.0). Out of 43 low pressure systems with intensity of T1.0 or above, 31 systems occurred over BOB and 12 over ARS. Similarly out of 43 systems, 8 systems occurred pre-monsoon, 7 during monsoon, 26 post-monsoon and 2 during winter season (table 3 ). The main purpose of this stratification is to calculate the quality measures according to the area of genesis, season of formation and intensity of the cyclogenesis.

To determine the skill of the model, various parameters like Probability of Detection (POD), Missing Rate (MR), False Alarm Ratio (FAR), Bias, Critical Success Index (CSI), Percentage Correct (PC), Correct Non-Occurrence (c-non) are determined using $2 \times 2$ contingency table as given below.

\begin{tabular}{lllll}
\hline & & \multicolumn{2}{c}{ Observed class } & \\
\cline { 2 - 4 } & & Yes & No & Total \\
\hline $\begin{array}{l}\text { Forecast } \\
\text { class }\end{array}$ & Yes & $\mathrm{a}$ & $\mathrm{b}$ & $\mathrm{a}+\mathrm{b}$ \\
Total & No & $\mathrm{c}$ & $\mathrm{d}$ & $\mathrm{c}+\mathrm{d}$ \\
& $\mathrm{a}+\mathrm{c}$ & $\mathrm{b}+\mathrm{d}$ & $\mathrm{a}+\mathrm{b}+\mathrm{c}+\mathrm{d}=\mathrm{n}$ \\
\hline
\end{tabular}

Hit Rate $(\mathbf{H})$ or Probability of Detection (POD): The H/POD is the fraction of observed events that is forecast correctly. It is calculated as follows:

$$
\frac{\mathrm{H}}{\mathrm{POD}}=\frac{\mathrm{a}}{(\mathrm{a}+\mathrm{c})}
$$

It ranges from zero $(0)$ at the poor end to one (1) at the good end.

Missing rate (MR): It is the fraction of observed event that could not be predicted. It is calculated as:

$$
\mathrm{MR}=\frac{\mathrm{c}}{(\mathrm{a}+\mathrm{c})}
$$

False Alarm Ratio (FAR): The FAR is the fraction of 'yes' forecasts that were wrong, i.e., were false alarms. It is calculated as follows:

$$
\mathrm{FAR}=\frac{\mathrm{b}}{(\mathrm{a}+\mathrm{b})}
$$

It ranges from zero (0) at the good end to one (1) at the poor end.

Correct non-occurrence (c-non): It is the fraction of 'No' events that are forecast correctly. It is calculated as:

$$
(\mathrm{c}-\text { non })=\frac{\mathrm{d}}{(\mathrm{b}+\mathrm{d})}
$$



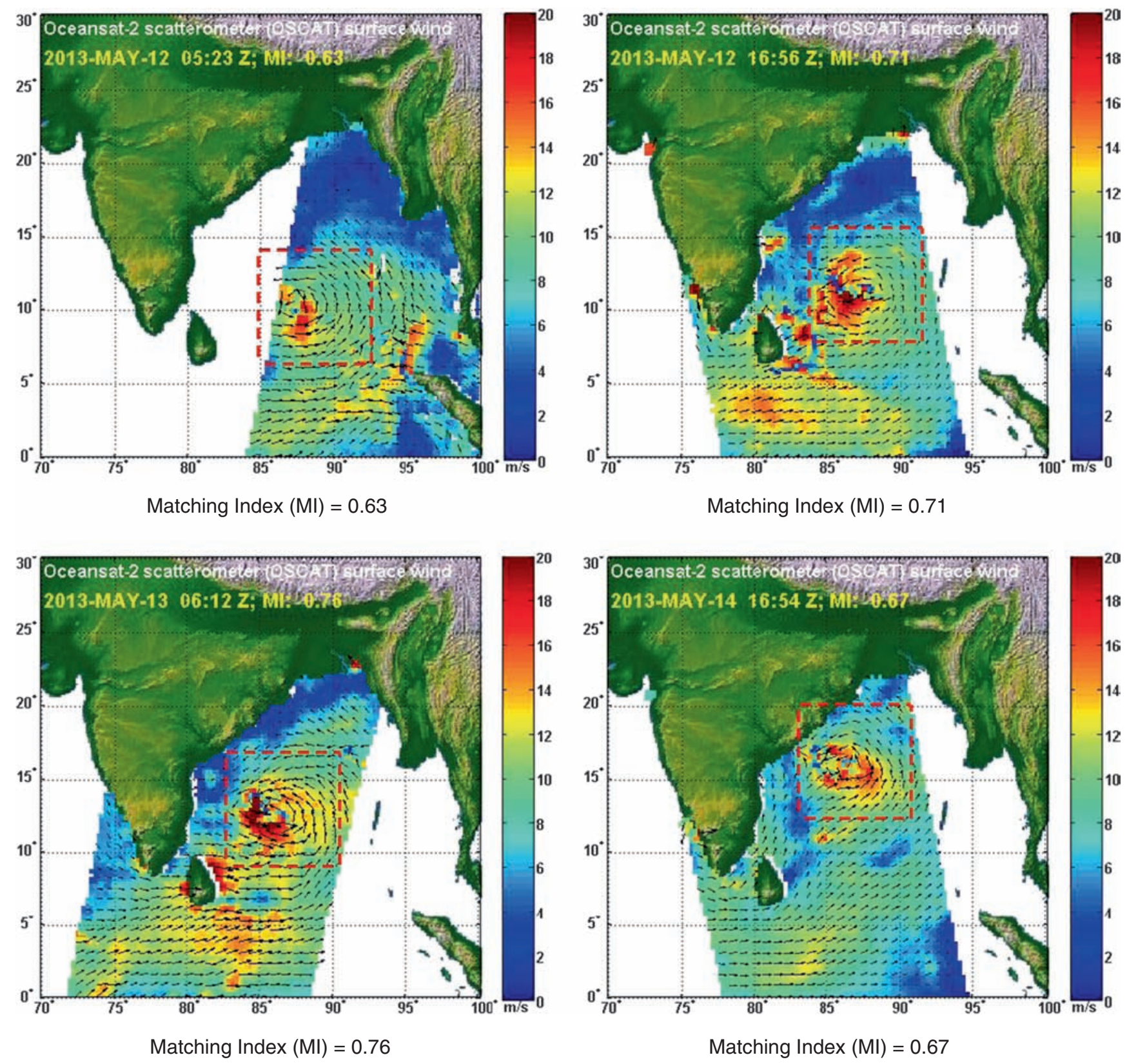

Figure 2. Scatterometric wind for cyclone Mahasen (8 May 2013-16 May 2013).

Threat Score (TS) or Critical Success Index (CSI): The TS or CSI combines H/POD and FAR into one score for low frequency events like cyclogenesis. It is calculated as follows:

$$
\mathrm{TS}=\mathrm{CSI}=\frac{\mathrm{a}}{(\mathrm{a}+\mathrm{b}+\mathrm{c})} \text {. }
$$

This score ranges from zero $(0)$ at the poor end to one (1) at the good end. It does not consider 'not forecast/not occurred' (d) events.

Bias (B): Bias compares the number of times an event was forecast to the number of times an event was observed. Specifically,

$$
\mathrm{B}=\frac{(\mathrm{a}+\mathrm{b})}{(\mathrm{a}+\mathrm{c})}
$$

If $\boldsymbol{B}=\mathbf{1}$ (unbiased), the occurrence of the event was forecast the same number of times that it was observed.

If $\boldsymbol{B}>\mathbf{1}$ (over-forecast), the occurrence of the event was forecast more than it was observed.

If $\boldsymbol{B}<\mathbf{1}$ (under-forecast), the occurrence of the event was forecast less than it was observed.

Bias calculation shows three categories overforecast, under-forecast and unbiased. The overforecast means false alarm and under-forecast means missing the event completely.

Percent Correct (PC): The PC is the percent of forecasts that are correct. Specifically,

$$
\mathrm{PC}=\frac{(\mathrm{a}+\mathrm{d})}{(\mathrm{a}+\mathrm{b}+\mathrm{c}+\mathrm{d})}=\frac{(\mathrm{a}+\mathrm{d})}{\mathrm{n}}
$$




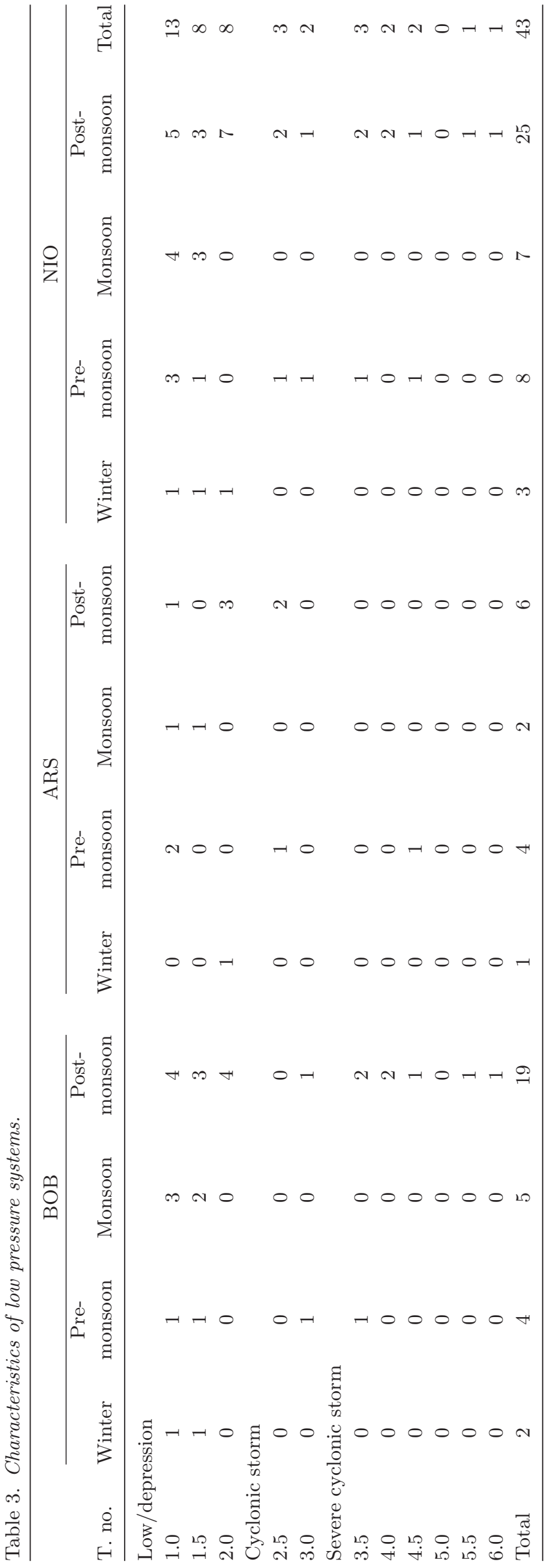

$\mathrm{PC}$ ranges from zero (0) for no correct forecasts to one (1) when all forecasts are correct.

It is not useful for low frequency events such as cyclogenesis. In these cases, there is a high frequency of 'not forecast/not occurred' (d) events. This gives high $\mathrm{PC}$ values that are misleading with regard to the forecasting of the low frequency event. This shortcoming is compensated for by calculating Heidke Skill Score (HSS). For the HSS, the reference measure is the proportion correct that would be expected by random forecasts that are statistically independent of the observations.

$\mathrm{HSS}=2(\mathrm{ad}-\mathrm{bc}) /[(\mathrm{a}+\mathrm{c})(\mathrm{c}+\mathrm{d})+(\mathrm{a}+\mathrm{b})(\mathrm{b}+\mathrm{d})]$

HSS is independent of $\mathrm{n}$. HSS $=1$ for a perfect forecast; HSS $=0$ shows no skill. If HSS $<0$, the forecast is worse than the reference forecast.

\section{Results and discussion}

The performance of the model with reference to basin of genesis, the season of genesis and the categories of low pressure systems are presented in sections 3.1, 3.2 and 3.3, respectively.

\subsection{Performance of model with respect to basin of formation}

Figure 3 shows the performance of the model according to the basin of genesis, i.e., BOB and ARS and NIO. The POD is 0.61 with MR of 0.39 . However, the FAR for NIO is very high, i.e., $64 \%$. The CSI and HSS for NIO shows a good forecasting skill, i.e., 0.29 and 0.07 , respectively. The comparison of skill score for BOB and ARS shows that the POD is higher for BOB than ARS, whereas FAR is higher for ARS than for BOB. It is mainly because of the fact that the BOB is climatologically more active than ARS. Further the sample size is larger in BOB than in ARS. The analysis of Bias parameter indicates that there is high overprediction by the model over the NIO with Bias as 1.73. However, the bias is higher over the $\mathrm{BOB}$ than over the ARS. The higher bias of occurrence means over-prediction of genesis. The CSI and PC are almost same for BOB and ARS. However, the HSS is higher over the BOB. Hence, to summarise, the performance of the model is better over the BOB than over the ARS. This may be due to the fact that the predictability of TCs over the ARS is less than that over BOB according, to Mohapatra et al. $(2013 \mathrm{a}, \mathrm{b})$. The genesis characteristics of TCs are also different for BOB and ARS (Mohapatra et al. 2012a, 2013a, b, 2014, 2015) due to different dynamical and thermodynamical properties over these basins. However, the bias/error in the 


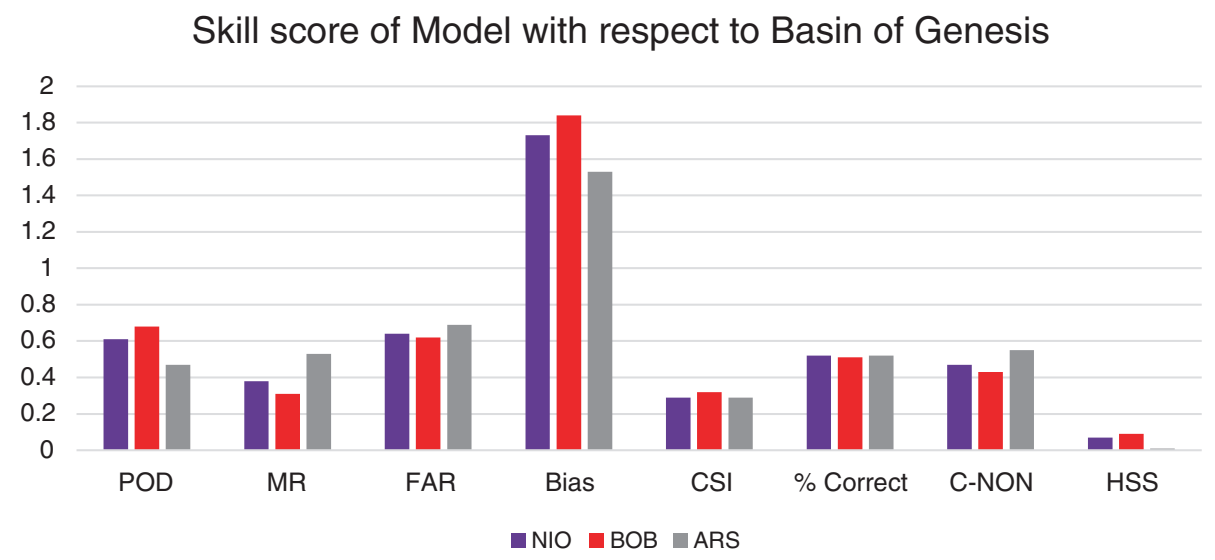

Figure 3. Skill scores of model forecast for cyclogenesis over BOB, Arabian Sea and NIO.

Comparision of Skill Scores of CPS (Kotal et al 2014) and Satellite based Cyclogenesis technique over NIO

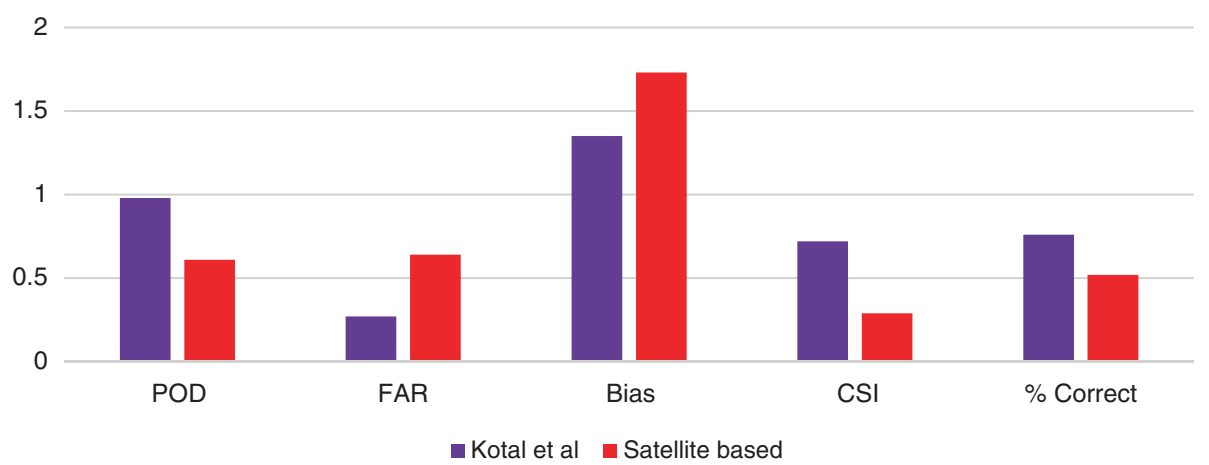

Figure 4. Comparison of satellite-based cyclogenesis technique with Skill score of cyclogenesis prediction system (Kotal et al. 2014) for TC over NIO.

\section{Skill score of Model with respect to season of genesis}

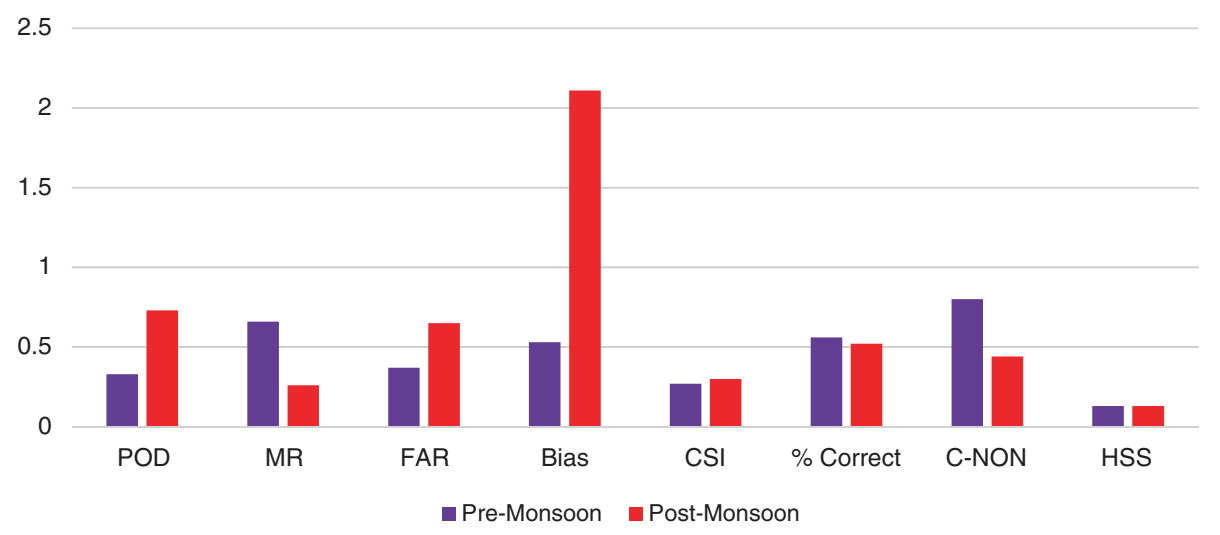

Figure 5. Scores of model forecast for cyclogenesis over NIO during pre-monsoon and post-monsoon seasons.

satellite estimation of sea surface winds through Oceansat-II and QuickSCAT needs to be investigated with respect to BOB and ARS. This study is limited over ARS, as the buys/ships network is limited over ARS.

The performance of dynamical-statistical model based cyclogenesis prediction using a genesis potential parameter (GPP) by Kotal et al. (2014) is shown in figure 4 along with the skill score of satellite-based cyclogenesis model. The skill scores of GPP are calculated for the TCs that occurred from 2008 to 2013. Figure 4 shows that the Bias and FAR of the satellite-based model are higher as compared to that of NWP-based model (Kotal 


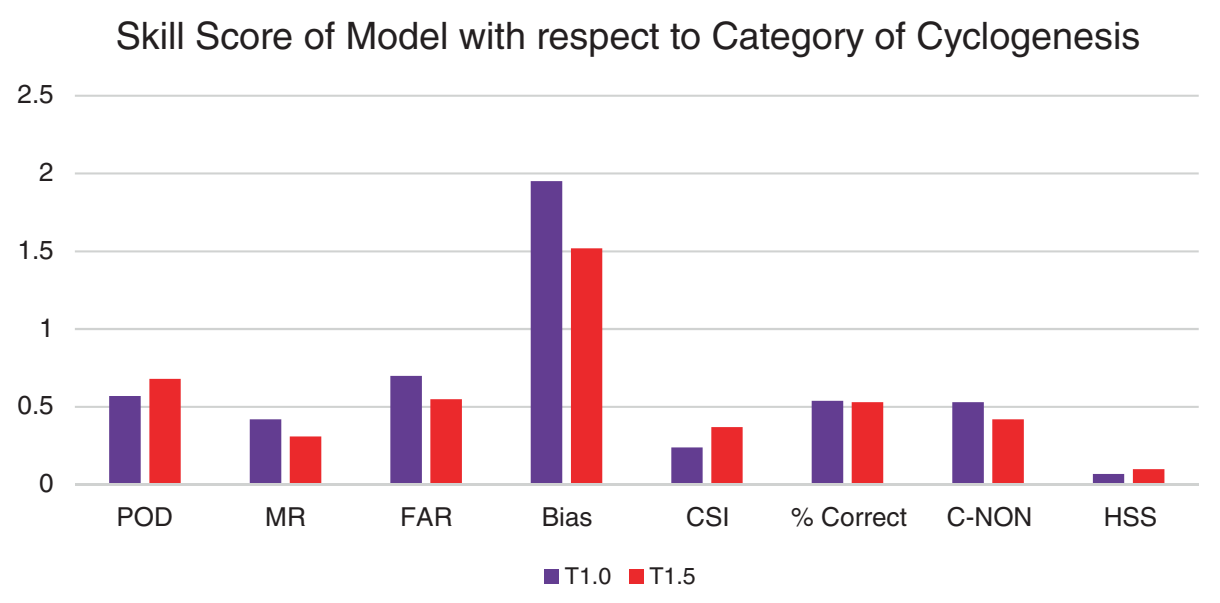

Figure 6. Skill scores of model forecast for cyclogenesis over NIO at different initial intensities.

et al. 2014). The POD of the satellite-based model is less than that of the NWP-based model. The CSI and PC are slightly higher for the GPP technique. It may be due to the fact that the satellite technique is purely based on analogues and does not take into account the dynamical and thermodynamical characteristics, which play a dominant role in cyclogenesis. The GPP technique is based on the dynamical and thermodynamical parameters derived from the forecast fields of IMD global forecast system (GFS) model. Details can be found out from Kotal et al. (2014).

\subsection{Performance of model with respect to season of formation}

Figure 5 shows the skill score of the model according to the different seasons, viz., the pre-monsoon and post-monsoon seasons. The result for winter season and monsoon are not presented as the number of the cases is very less. Comparing the skill score in different seasons, the POD is significantly higher for post-monsoon season as compared to pre-monsoon season. At the same time, the FAR is also higher during post-monsoon season than in pre-monsoon season. There is very high over-prediction in post-monsoon season and underprediction in pre-monsoon season. It may be due to the fact that the post-monsoon season is climatologically more active than the pre-monsoon season and hence the sample size is larger in postmonsoon season. The c-non is higher during premonsoon season. The CSI and HSS are nearly same for both the seasons. Hence the model shows better performance during post-monsoon than in the premonsoon season, with respect to POD only. It has been proved by Mohapatra et al. (2013a, b), also with respect to track and intensity of TCs that the forecast skill is higher during post-monsoon season than in the pre-monsoon season.
Table 4. Number of runs of model based in T1.0, T1.5 and T2.0.

\begin{tabular}{lc}
\hline $\begin{array}{l}\text { T. No. at the time } \\
\text { of model run }\end{array}$ & $\begin{array}{c}\text { No. of } \\
\text { cases }\end{array}$ \\
\hline T1.0 & 83 \\
T1.5 & 47 \\
T2.0 & 24 \\
\hline
\end{tabular}

\subsection{Performance of model with respect initial intensity (T1.0, T1.5 and T2.0)}

Figure 6 shows the performance of the model according to different initial intensities of the systems, i.e., T1.0 and T1.5. The performance of model for T1.5 is better than T1.0, as the POD is higher. FAR, MR and Bias are also low for T1.5, as compared to T1.0. The CSI and HSS are also higher in case of T1.5 than in T1.0. Since the potential matching index is only based on sea surface wind, the method mainly lacks in predicting the potential cyclogenesis, especially at the stage LLC and T1.0, due to absence of other crucial dynamical and thermodynamical parameters known to have profound influence on cyclogenesis.

The comparison of the performance of the model based on intensity ( $\mathrm{T}$ Number) at the time of model run has been carried out. For this purpose we have considered the model runs at the intensity stage of T1.0 and T1.5. The number of such cases are 83 and 47 , respectively (table 4 ). The number of cases with T2.0 is very less (only 24). Hence, though the model has been run for all such cases with T2.0 at the time of model run, only the comparative analysis for $\mathrm{T} 1.0$ and $\mathrm{T} 1.5$ are presented here.

\section{Conclusion}

Cyclogenesis prediction model is an important approach towards forecasting of the formation of 
cyclones from T1.5, i.e., from the depression stage, as per IMD classification. The model runs at the intensity stage of T1.5 shows the POD of 0.68 with FAR of 0.55 , Bias of 1.52, CSI of 0.37 and HSS of 0.1 for all the systems in prediction of cyclogenesis (T2.5) over the NIO. However, the performance of the model is better when initiated at T1.5 stage of the intensity.

The performance of the model is better postmonsoon than in the pre-monsoon season. Its performance is better over the BOB than over the ARS. The performance of the model increases with increase in intensity from T1.0 to T1.5, at the time of running of the model. In general, the performance of the model is better in those ocean basins and seasons which experience more frequent cyclogenesis. In other words, a large sample size is good for a better performance of this model.

Comparing the performance of this satellitebased technique with the dynamical statistical model used by IMD (Kotal et al. 2014), the FAR and Bias are higher in case of satellite technique. The CSI, HSS and PC are also slightly less, in case of satellite technique presented in this study. This may be due to the fact that the satellite technique is purely based on analogues and does not take into account the dynamical and thermodynamical characteristics which play dominant roles in cyclogenesis.

The study is based on a limited period of data due to non-availability of scatterrometer over the region. It can be further improved by the launch of new scatterometer-based satellites in the future. Further, the technique can be improved by considering other cyclogenesis parameters like sea surface temperature, ocean thermal energy, low level vorticity, vertical wind shear, moist static stability, relative humidity in lower and middle tropospheric levels, etc., along with the surface wind.

\section{Acknowledgements}

The authors acknowledge the support provided by Space Application Centre, Ahmedabad for providing the technique and National Remote Sensing Centre, Hyderabad, for providing the scatterometric winds data. The authors extent their thanks to the satellite division, IMD, for providing necessary help during the study period.

\section{References}

Bourassa M A and McBeth-Ford K 2010 Uncertainty in scatterometer derived vorticity; J. Atmos. Ocean. Technol. 27 594-603.

Charney J G and Eliassen A 1964 On the growth of the hurricane depression; J. Atmos. Sci. 21 68-75.
Chelton D B, Wentz F J, Gentemann C L, de Szoeke R A and Schlax M G 2004 Satellite measurements reveal persistent small-scale features in ocean winds; Science 303 978-983.

Demirci O, Tyo J S and Ritchie E A 2007 Spatial and spatiotemporal projection pursuit techniques to predict the extratropical transition of tropical cyclones; IEEE Trans. Geosci. Remote Sens. 45 418-425.

Dvorak V F 1975 Tropical cyclone intensity analysis and forecasting from satellite imagery; Mon. Wea. Rev. 103 420-430.

Dvorak V F 1984 Tropical cyclone intensity analysis using satellite data; NOAA Technical Report NESDIS 11 47p.

Gray W M 1975 Tropical cyclone genesis; Colorado State Univ., Dept. Atmos. Sci. Paper No. 234 121p.

Hite M M, Bourassa M A, Cunningham P, O'Brien J $\mathrm{J}$ and Reasor P D 2007 Vorticity-based detection of tropical cyclogenesis; J. Appl. Meteorol. Climatol. 46 1214-1229.

IMD 2013 Cyclone Warning in India: Standard Operation Procedure; IMD, New Delhi.

Jaiswal N and Kishtawal C M 2011 Prediction of tropical cyclogenesis using scatterometer data; IEEE Trans. Geosci. Remote Sens. 49 4904-4909.

Katsaros K B, Forde P, Chang E B and Liu W T 2001 QuikSCAT facilitates early identification of tropical depressions in 1999 hurricane season; Geophys. Res. Lett. 28(6) 1043-1046.

Kotal S D, Kundu P K and Roy Bhowmik S K 2009 Analysis of cyclogenesis parameter for developing and nondeveloping low pressure systems over the Indian Sea; Nat. Hazards 50 389-402.

Kotal S D, Bhattacharya S K and Roy Bhowmik S K 2014 Development of NWP based objective cyclone prediction system (cps) for north Indian Ocean tropical cyclones - Evaluation of performance; Tropical Cyclone Research and Review 3 162-177.

Li T, Fu B, Ge X, Wang B and Peng M 2003 Satellite data analysis and numerical simulation of tropical cyclone formation; Geophys. Res. Lett. 302122.

Liu G, Curry J A and Clayson C A 1995 Study of tropical cyclogenesis using satellite data; Meteor. Atmos. Phys. 56 111-123.

Mohapatra M 2015 Cyclone hazard proneness of districts of India; J. Earth Syst. Sci. 124 589-601.

Mohapatra M, Mandal G S, Bandyopadhyay B K, Tyagi A and Mohanty U C 2012a Classification of cyclone hazardprone districts of India; Nat. Hazards 63 16011620 .

Mohapatra M, Bandyopadhyay B K and Ajit Tyagi 2012b Best track parameters of tropical cyclones over the North Indian Ocean: A review; Nat. Hazards 63 1285-1317.

Mohapatra M, Nayak D P, Sharma R P and Bandyopadhyay B K 2013a Evaluation of official tropical cyclone track forecast over north Indian Ocean issued by India Meteorological Department; J. Earth Syst. Sci. 122 589-601.

Mohapatra M, Bandyopadhyay B K and Nayak D P 2013b Evaluation of operational tropical cyclone intensity forecasts over north Indian Ocean issued by India Meteorological Department; Nat. Hazards 68 433-451.

Mohapatra M, Bandyopadhyay B K and Tyagi A 2014 Construction and quality of best tracks parameters for study of climate change impact on Tropical Cyclones over the North Indian Ocean during satellite era; In: Monitoring and prediction of tropical cyclones over the Indian Ocean and climate change (eds) Mohanty U C, Mohapatra M, Singh O P, Bandyopadhyay B K and Rathore L S, Co-published by Springer and Capital Publishers, New Delhi, India, pp. 1-17. 
Mohapatra M, Geetha B, Balachandran S and Rathore L S 2015 On the tropical cyclone activity and associated environmental features over north Indian Ocean in the context of climate change; J. Climate Change 1 1-26.

Ooyama K V 1969 Numerical simulation of the life cycle of tropical cyclones; J. Atmos. Sci. 26 3-40.

Pineros M F, Ritchie E A and Tyo J S 2010 Detecting tropical cyclone genesis from remotely sensed infrared image data; IEEE Geosci. Remote Sens. Lett. 7 826-830.

Schumacher A B, DeMaria M and Knaff J A 2009 Objective estimation of 24-h probability of tropical cyclone formation; Wea. Forecasting 24 456-471.

Sharp R J, Bourassa M A and O'Brien J J 2002 Early detection of tropical cyclones using SeaWinds-derived vorticity; Bull. Am. Meteor. Soc. 83 879-889.
Wang L, Lau K-H, Fung C-H and Gan J-P 2007 The relative vorticity of ocean surface winds from the QuikSCAT satellite and its effects on the geneses of tropical cyclones in the South China Sea; Tellus A 59 $562-569$.

Wang L, Lau K-H, Zhang Q-H and Fung C-H 2008 Observation of non-developing and developing tropical disturbances over the South China Sea using SSM/I satellite; Geophys. Res. Lett. 35 1-5.

Zehr R M 1988 Satellite diagnosis of tropical cyclones; In: Proc. 3rd Conf. Satellite Meteorol. Oceanogr., Anaheim, CA, pp. 241-246.

Zehr R M 1992 Tropical cyclogenesis in the western north Pacific, U.S. Dept. Commerce, Washington, DC, NOAA Tech. Rep. NESDIS 61 181p.

MS received 29 July 2015; revised 4 July 2016; accepted 5 July 2016

Corresponding editor: A K SAHAI 